\title{
Induction of chromosome shattering by ultraviolet irradiation and caffeine: comparison of whole-cell and partial-cell irradiation
}

\author{
C. Cremer ${ }^{1 *}$, T. Cremer ${ }^{2}$, C. Zorn ${ }^{1}$ and J. Zimmer ${ }^{1}$ \\ ${ }^{\prime}$ Institut für Humangenetik und Anthropologie, Universität Freiburg, Albertstr. 11, D-7800 Freiburg i. Br. \\ (Federal Republic of Germany) and ${ }^{2}$ Institut für Anthropologie und Humangenetik, Universität Heidelberg. \\ Im Neuenheimer Feld 928, D-6900 Heidelberg (Federal Republic of Germany)
}

(Received 5 January 1981)

(Revision received 10 June 1981)

(Accepted 12 June 1981)

\section{Summary}

Synchronized and asynchronously growing cells of a V79 sub-line of the Chinese hamster were either whole-cell irradiated $(\lambda, 254 \mathrm{~nm})$ or laser-UV-microirradiated $(\lambda, 257 \mathrm{~nm})$. Post-incubation with caffeine $(1-2 \mathrm{mM})$ often resulted in chromosome shattering, which was a rare event in the absence of this compound. In experiments with caffeine, the following results were obtained.

Shattering of all the chromosomes of a cell (generalized chromosome shattering, GCS) was induced by whole-cell irradiation at the first post-irradiation mitosis when the UV fluence exceeded a "threshold" value in the sensitive phases of the cell cycle (Gl and S). GCS was also induced by laser-UV-microirradiation of a small part of the nucleus in $\mathrm{Gl}$ or $\mathrm{S}$ whereas microirradiation of cytoplasm beside the nucleus was not effective. An upper limit of the UV fluence in the non-irradiated nuclear part due to scattering of the microbeam was experimentally obtained. This UV fluence was significantly below the threshold fluence necessary to induce GCS in whole-cell irradiation experiments. In other cells, partial nuclear irradiation resulted in shattering of a few chromosomes only, while the majority remained intact (partial chromosome shattering, PCS). G1/early $S$ was the most sensitive phase for induction of GCS by whole-cell and partial nuclear irradiation. The frequency of PCS was observed to increase when partial nuclear irradiation was performed either at lower incident doses or at later stages of S. We suggest that PCS and GCS indicate 2 levels of chromosome damage which can be produced by the synergistic action of UV irradiation and caffeine. PCS may be restricted to microirradiated chromatin whereas

\footnotetext{
* Present address: Biomedical Sciences Division, Lawrence Livermore National Laboratory, Livermore, CA 94550 (U.S.A.).
} 
GCS involves both irradiated and unirradiated chromosomes in the microirradiated nucleus.

There is general agreement that DNA represents the essential target for most clastogenic agents, and mis-repair or misreplication of damaged DNA strands are considered to be responsible for the formation of chromosomal aberrations (Wolff, 1972; Bender et al., 1973; Evans, 1977; Kihlman, 1977; Kihlman et al., 1978; Leenhouts and Chadwick, 1978). This concept is also accepted for the synergistic action of clastogens with S-phase-dependent effect (e.g. UV radiation or alkylating agents) and caffeine post-treatment in rodent cells. In this case, chromosomal aberrations are postulated to occur in damaged chromatin owing to interference of caffeine with replication of damaged DNA strands (daughter strand repair, "postreplication repair"; Kihlman et al., 1974; Roberts et al., 1974; Nilsson and Lehmann, 1975; Kihlman, 1977; Roberts, 1978). A particular characteristic of this system is the frequent and abrupt appearance of metaphase plates, in which all chromosomes are shattered (generalized chromosome shattering, GCS), while other metaphase plates remain intact or show single chromosomal aberrations (Kato, 1973; Roberts et al., 1974; Nilsson and Lehmann, 1975; C. Cremer et al., 1980b). In this investigation, we compared the effects of whole-cell irradiation $(\lambda, 254 \mathrm{~nm})$ and of microirradiation $(\lambda, 257 \mathrm{~nm})$ of either a small part of the nucleus or of cytoplasm beside the nucleus, using a V79 sub-line of Chinese hamster cells. GCS was found to be a "threshold" phenomenon and was induced with high yields both by whole-cell irradiation and by microirradiation of the nucleus, when cells were post-treated with caffeine. A part of the metaphase plates obtained after microirradiation of the nucleus and post-incubation with caffeine showed fragmentation or pulverization of a few chromosomes only, while the majority of chromosomes remained intact (partial chromosome shattering, PCS). The effects of the UV dose and the phase of the cell cycle during irradiation on the yield of GCS and PCS, respectively, were investigated in detail. The results are discussed with reference to the phenomenon of "chromosome pulverization" described by other authors (for review see Nichols, $1970,1974)$ and interpreted in the light of a recently proposed factor depletion model (T. Cremer et al., 1980, 1981).

\section{Material and methods}

\section{Cell material and culture conditions}

If not stated otherwise, cells of a sub-line of V79 Chinese hamster cells were used and grown under standard conditions. Asynchronous cultures were inoculated into 6-cm plastic petri dishes after trypsination of subconfluent cultures (Cremer et al., 1976).

Synchronous cell populations were obtained by shaking off mitotic cells from growing cultures resulting in at least $90 \%$ synchrony (C. Cremer et al., 1980b). Autoradiography of synchronized V79 cells performed after a pulse with ${ }^{3} \mathrm{H}-\mathrm{TdR}$ at 
different times after mitotic selection indicated that the majority $(70-80 \%)$ of cells were still in Gl $3 \mathrm{~h}$ after mitotic selection, while $80-90 \%$ of the cells had entered S-phase after $5 \mathrm{~h}$.

In some microirradiation experiments, a 30 -min pulse of $\left[{ }^{3} \mathrm{H}\right]$ thymidine $(0.1$ $\mu \mathrm{Ci} / \mathrm{ml}, 5 \mathrm{Ci} / \mathrm{mM}$ ) was applied immediately before harvest of mitotic cells. Microirradiated cells that appeared labeled after autoradiography were eliminated from further consideration. The number of such cells turned out to be negligible.

Cells from a fibroblastoid diploid strain "CHL" derived from lung cells of a female Chinese hamster (Zorn et al., 1976), grown under the same conditions as the V79 cells, were used for the investigation of unscheduled DNA synthesis (UDS) since, in contrast to the V79 cells, these cells could easily be held in Gl phase by serum starvation. After UV irradiation $(\lambda, 254 \mathrm{~nm})$, UDS could be detected in the CHL cells at UV fluences as low as $0.4 \mathrm{~J} / \mathrm{m}^{2}$ (Cremer et al., 1978).

\section{UV irradiation}

Whole cell irradiation at wavelength $254 \mathrm{~nm}$ was carried out as described (C. Cremer et al., 1980b).

For microirradiation, cells grown in dishes were provided with HEPES-buffered, serum-free medium and were transferred to a special irradiation chamber (C. Cremer et al., 1976). Cells that were located within an array of $6 \times 6$ squares of $0.25 \mathrm{~mm}^{2}$ each ("experimental field") marked by scalpel cuts in the bottom of the petri dish were laser-UV-microirradiated at wavelength $257 \mathrm{~nm}$ (C. Cremer et al., 1974, 1976) either at one randomly selected site in the nucleus (nucleoli were excluded) or at one site in the cytoplasm about $4-5 \mu \mathrm{m}$ beside the nucleus. A spot diameter of $1-2 \mu \mathrm{m}$ with a UV power of $1 \times 10^{-8} \mathrm{~W}$ incident on the cell surface was used.

Only cells that were well spread and showed a nucleus clearly distinguishable by phase-contrast observation (Zeiss Ultrafluar $32 / 0.40 \mathrm{Ph}$ ) were microirradiated with a given UV dose. Cells that did not meet these criteria were microirradiated lethally at a high dose sufficient to prevent these cells from entering a subsequent mitosis (C. Cremer et al., 1976). Cells growing outside the experimental fields as well as cells in other dishes exposed to the same experimental schedule except for microirradiation served as controls (control field).

\section{Post-irradiation treatment and chromosome preparation.}

After irradiation, cells were grown at $37^{\circ} \mathrm{C}$ in medium with $10 \%$ fetal calf serum for different times either in the presence or in the absence of caffeine. Colchicine $(2 \mu \mathrm{g} / \mathrm{ml})$ was added for $3 \mathrm{~h}$ before chromosome preparations were made as described (Zorn et al., 1976). The preparations were air-dried and stained with acetic orcein.

In whole-cell irradiation experiments, at least 100 randomly selected metaphase plates per dish were evaluated for chromosome alterations. In microirradiation experiments, all metaphase plates situated in the "experimental fields" were scored.

Pulse labeling $(2 \mathrm{~h})$ of microirradiated cells with $\left[{ }^{3} \mathrm{H}\right]$ thymidine $(10 \mu \mathrm{Ci} / \mathrm{ml}, 47$ $\mathrm{Ci} /$ mmole) and autoradiography was carried out as described (Zorn, 1978; Zorn et al., 1979). 
For statistical evaluation (C. Cremer et al., 1980b) the binomial assumption was made, and the confidence limits $p_{1} \leqslant p \leqslant p_{2}$ for proportions were determined. $P$ is the observed frequency and $p_{1}$ and $p_{2}$ are the lower and upper limits of the 95\% confidence interval, respectively. When the term "significant difference" was used, the $95 \%$ confidence intervals of $p_{1}$ and $p_{2}$ were clearly separated from each other.

\section{Results}

Types of aberrant metaphase plates found after UV irradiation (whole-cell irradiation or partial nuclear irradiation) and post-treatment with caffeine

Either whole-cell UV irradiation or UV microirradiation of a small part of a nucleus (partial nuclear irradiation) of V79 Chinese hamster cells was performed and the cells were post-incubated with caffeine. Mitotic cells were sampled with colchicine, scored for chromosomal damage and classified according to the following criteria (C. Cremer et al., 1980b; T. Cremer et al., 1980).

Class A: Chromosome appeared intact. Class B: 1 or 2 aberrations were found (mostly achromatic lesions, or chromatid breaks). Class $C$ : more than 2 aberrations were observed but the majority of the chromosomes ( 11 and more) remained intact. After partial nuclear irradiation, severely damaged chromosomes were often observed that were clearly concentrated at a small part of the metaphase plate and that were surrounded by intact chromosomes (Fig. la), in contrast with class-C figures obtained after whole-cell irradiation where such a striking concentration was found only rarely.

Class $D$ aberrations were observed in the majority of chromosomes ( 11 and more), but still one or several chromosomes appeared intact. Class $E$ : all chromosomes were affected, appearing fragmented and/or pulverized (generalized chromosome shattering, GCS). The term "generalized chromosome shattering" is introduced as a descriptive one to avoid any prejudice about the continuity or discontinuity of the DNA strand in these chromosomes. Subclass El: in spite of a high number of aberrations, the chromosomal fragments could still be recognized at least in a part of the metaphase plate. Subclass E2: the whole chromosome complement appeared "pulverized" (Freed and Schatz, 1969; Nichols, 1970, 1974; Zorn et al., 1976; C. Cremer et al., 1980b; T. Cremer et al., 1980, 1981).

After partial nuclear irradiation, a "damage center" could sometimes be recognized: in classes D and E1 it consisted of pulverized chromosome segments while the surrounding chromosomes were fragmented (Fig. 1b). By contrast, this "damage center" was not observed after whole-cell irradiation. In cells of class E2, in most cases pulverization obtained after partial nuclear irradiation was rather uniform and could not be distinguished from GCS obtained after whole-cell irradiation (Fig. 1d).

Quantitative evaluation of whole-cell irradiation experiments

(1) UV Irradiation of asynchronous cultures. Fig. 2 shows a quantitative evalua- 

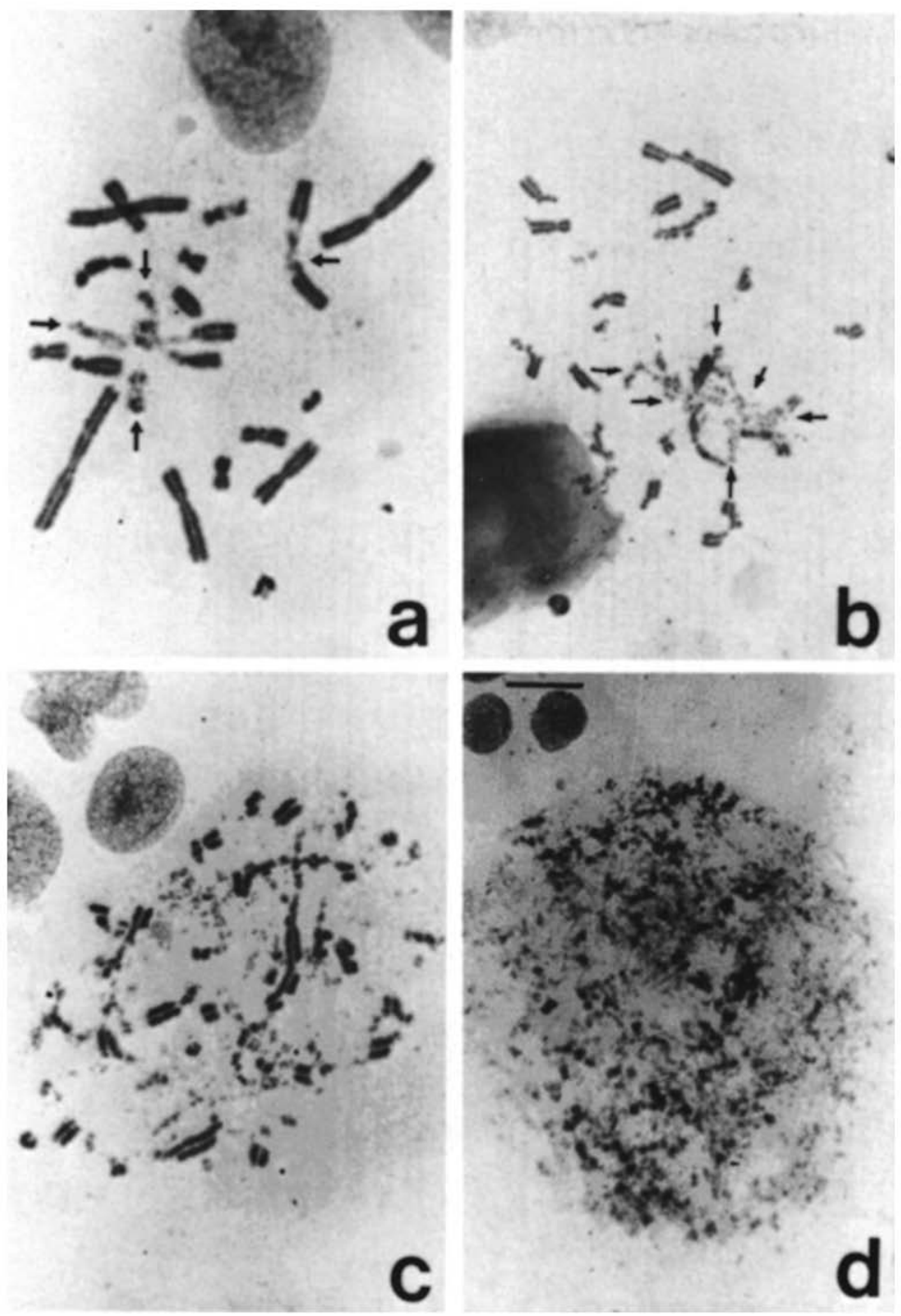

Fig. 1. Chromosome shattering produced by partial nuclear irradiation $(\lambda, 257 \mathrm{~nm})$ and caffeine post-treatment. Partial nuclear irradiation was carried out $4 \mathrm{~h}$ after mitotic selection with an incident UV energy of $0.13 \mathrm{~nJ}$ per nucleus. Chromosome preparation was performed after $15 \mathrm{~h}$ of post-incubation with $1 \mathrm{mM}$ caffeine. (a) Chromosome damage (arrows) is restricted to a part of the metaphase plate. (b) Chromosomes are severely fragmented. A "damage center" consisting of pulverized chromosomes is indicated by arrows. (c) Fragmented and pulverized chromosome segments. A "damage center" is not recognized in this metaphase plate. (d) Pulverization of the chromosome complement. $\mathrm{Bar}=10 \mu \mathrm{m}$.

tion of metaphase plates obtained after UV irradiation of asynchronous V79 cultures and different post-incubation periods $(3-24 \mathrm{~h})$ in the presence of 0,1 and $2 \mathrm{mM}$ caffeine. GCS was the predominant type of damaged metaphase plate after posttreatment with caffeine and occurred after a delay of several hours. With increasing 


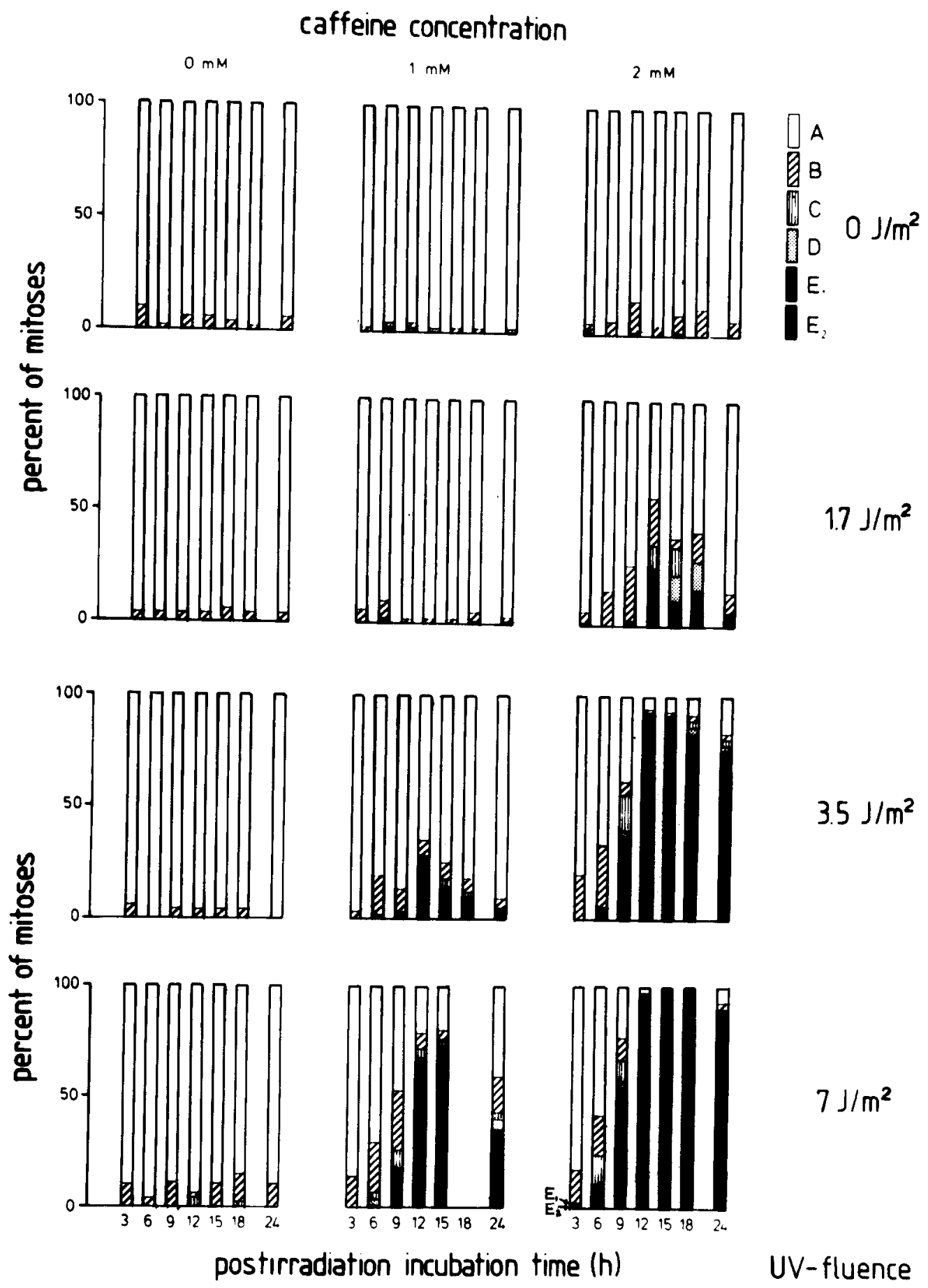


a

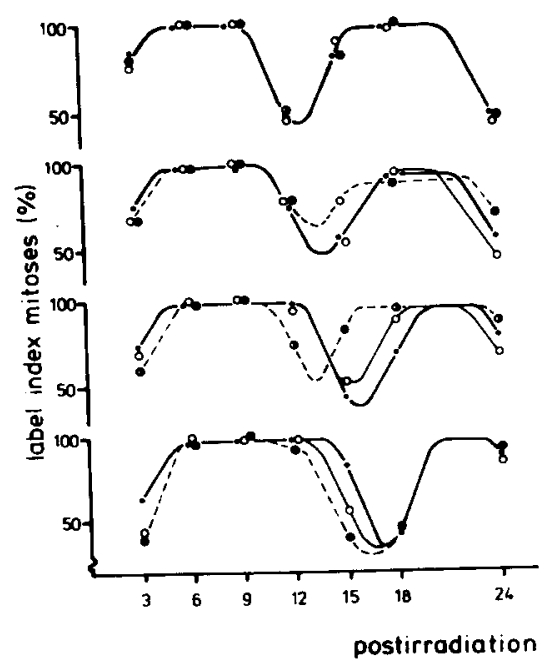

b

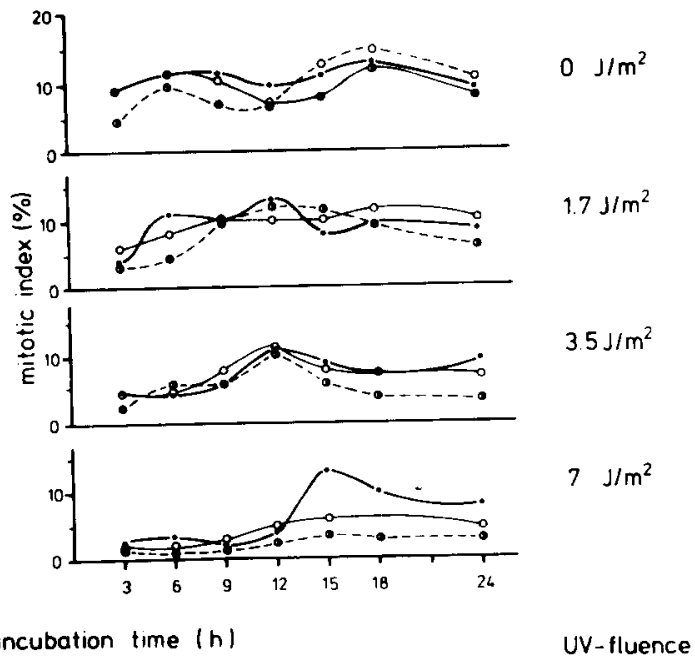

Fig. 3. Whole-cell UV irradiation $(\lambda, 254 \mathrm{~nm})$ of unsynchronized V79 cells and post-incubation with caffeine (same experiment as shown in Fig. 2). (a) Metaphase labeling index (MLI). (b) Mitotic index (MI). - no caffeine; $O, 1 \mathrm{mM}$ caffeine; $12 \mathrm{mM}$ caffeine. For each value, at least 100 mitotic cells (MLI) and 500 cells (MI) were scored.

UV fluence and/or caffeine concentration, the metaphase plates with GCS appeared earlier after irradiation, indicating that the length of S-phase traverse necessary to produce this effect depended on both these parameters.

Concerning the respective maximal percentage of cells with GCS, the following results were obtained. (a) $0 \mathrm{mM}$ caffeine: no significant differences were obtained between different UV fluences. (b) $0 \mathrm{~J} / \mathrm{m}^{2}$ : no significant differences were obtained between 0,1 and $2 \mathrm{mM}$ caffeine. (c) $1 \mathrm{mM}$ caffeine: significant differences were found between 1.7 and $3.5 \mathrm{~J} / \mathrm{m}^{2}$ and between 3.5 and $7 \mathrm{~J} / \mathrm{m}^{2}$. (d) $2 \mathrm{mM}$ caffeine: significant differences existed between $0,1.7$ and $3.5 \mathrm{~J} / \mathrm{m}^{2}$. The difference between 3.5 and $7.0 \mathrm{~J} / \mathrm{m}^{2}$ was not significant.

In the experiments presented in Fig. 2 , the cultures received $\left[{ }^{3} \mathrm{H}\right]$ thymidine $(0.1$ $\mu \mathrm{Ci} / \mathrm{ml}$ ) for $30 \mathrm{~min}$ immediately before irradiation. An evaluation of the label index

Fig. 2. Chromosome damage produced by whole-cell UV irradiation $(\lambda, 254 \mathrm{~nm})$ of unsynchronized cells and post-incubation with caffeine. UV fluences delivered to asynchronously growing V79 cell cultures are indicated at the right side of the diagram (identical UV fluences for all 3 graphs in a given horizontal row). Cultures were post-incubated in the absence or presence of caffeine at concentrations indicated at the top of the diagram (identical caffeine concentrations for all $4 \mathrm{graphs}$ in a given vertical row). Mitotic cells were sampled at different times after irradiation as indicated at the bottom of the diagram (abscissa) and classified according to the extent of chromosome damage in classes A-E2. In each culture a sample of at least 100 mitotic cells was considered. All cultures were irradiated and post-treated in a single experimental set-up. 
of mitotic cells (Fig. 3a) confirmed that UV irradiation in G2 did not induce GCS at the first post-irradiation mitosis (C. Cremer et al., 1980b) and suggested that a $\mathrm{UV}$-induced increase in the length of the $\mathrm{S}$ phase might be partially reduced by caffeine post-treatment. Caffeine alone had no observable effect on the duration of the cell cycle as compared with untreated controls.

An evaluation of the mitotic index (Fig. 3b) indicated a depression, which depended on the UV fluence delivered to the cells and on the caffeine concentration. After treatment by caffeine alone, the mitotic indices showed little if any alteration during the 24-h period under investigation.

(2) UV Irradiation of synchronized cells during GI and S. Cells were irradiated either $3 \mathrm{~h}$ after mitotic selection (corresponding to late $\mathrm{G} 1$ phase in the majority of the cells) or $6 \mathrm{~h}$ after mitotic selection corresponding to $S$ phase.

After exposure of synchronized cultures to UV fluences between 0 and $7 \mathrm{~J} / \mathrm{m}^{2}$, the respective peaks of mitotic cells were observed between 16 and $21 \mathrm{~h}$ after mitotic selection. To account for the mitotic delay with increasing dose, chromosome preparations were established after different incubation times.

The dose-effect curves for GCS obtained after incubation with $1 \mathrm{mM}$ caffeine (Fig. 4) indicate the existence of a certain "threshold" UV fluence as already suggested by experiments with asynchronous cultures (Fig. 2). Metaphase plates with shattered chromosomes were only rarely observed for fluences up to $1.7 \mathrm{~J} / \mathrm{m}^{2}$, and their percentage was not significantly increased as compared with unirradiated cells. Above this value, however, a steep increase in the percentage of cells with GCS was obtained. The increase of the percentage of cells with GCS between 1.7 and $3.4 \mathrm{~J} / \mathrm{m}^{2}$ was statistically significant for all incubation times. A detailed evaluation of the

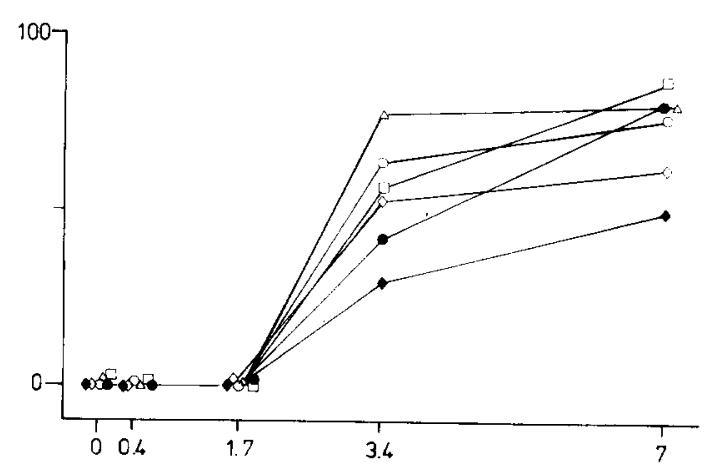

Fig. 4. Generalized chromosome shattering (GCS) obtained after whole-cell UV irradiation ( $\lambda, 254 \mathrm{~nm})$ of synchronized V79 cells and post-incubation with $1 \mathrm{mM}$ caffeine. Ordinate, percentage of mitotic cells with GCS (classes El + E2) following irradiation $3 \mathrm{~h}$ (open symbols) or $6 \mathrm{~h}$ (closed symbols) after mitotic selection. Abscissa, UV fluence $\left(\mathrm{J} / \mathrm{m}^{2}\right)$. Chromosome preparations were made at $15 \mathrm{~h}(\diamond, \diamond), 18 \mathrm{~h}$ $(O, O), 21 \mathrm{~h}(\triangle)$, and $24 \mathrm{~h}(\square)$ after mitotic selection. The points at UV fluences $0,0.4$ and $1.7 \mathrm{~J} / \mathrm{m}^{2}$ are superimposable (no significant differences). Each point represents evaluation of at least 100 mitotic cells. 
distribution of damage classes $A-E 2$ revealed that the sum of classes $A$ and $E$ comprised the majority of mitotic cells at all UV fluences investigated. In agreement with data from other authors (Nilsson and Lehmann, 1975), this suggests that the increase of mitotic cells with a shattered chromosome complement (class E) occurs as a rather abrupt change from cells with no or single aberrations (classes $\mathrm{A}, \mathrm{B}$ ) to cells with GCS. A similar outcome was observed after whole-cell irradiation of synchronized cells and post-incubation with $2 \mathrm{mM}$ caffeine: here, however, a significant increase of the number of cells with GCS was found for UV fluences above 0.9 $\mathrm{J} / \mathrm{m}^{2}$.

\section{Microirradiation experiments}

(1) Influence of post-irradiation incubation time on the extent of chromosome damage in mitoses obtained after partial nuclear irradiation. V79 cells from asynchronous cultures were microirradiated by $1 \mathrm{~nJ}$ incident UV energy per nucleus and thereafter incubated for various times $(7-16 \mathrm{~h})$ in the presence of caffeine $(1 \mathrm{mM})$ before chromosome preparations were made. The distribution of metaphases into classes A-E2 is shown in Fig. 5.

For the different incubation times, a considerable variation was noted with regard to the damaged metaphase plates attributed to classes C-E2. A comparison of shorter incubation times $(7 \mathrm{~h})$ with longer incubation times $(16 \mathrm{~h})$, presumably corresponding to microirradiation later in $\mathrm{S}$ phase and some earlier stages of the cell

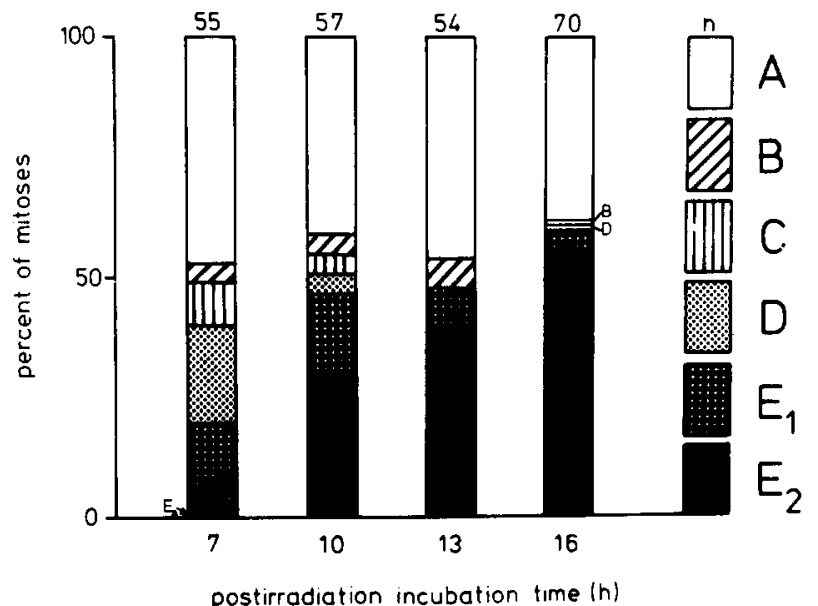

Fig. 5. Chromosome damage produced by UV microirradiation $(\lambda, 257 \mathrm{~nm})$ of the cell nucleus of asynchronous $V 79$ cells and post-treatment with caffeine $(1 \mathrm{mM})$ for different periods of time $(7-16 \mathrm{~h})$. A small part of the cell nucleus was microirradiated with an incident UV energy of I nJ. Chromosome preparation was performed at times indicated below the columns. Mitotic cells were classified in damage classes A-E2. The distribution of these classes at different post-irradiation times is shown by columns. The number $n$ of evaluated mitotic cells is given at the top of each column. 
TABLE 1

EVALUATION OF FIRST POST-IRRADIATION METAPHASE PLATES OBTAINED AFTER MICROIRRADIATION OF THE CYTOPLASM BESIDE THE CELL NUCLEUS AND POST-TREATMENT WITH CAFFEINE

\begin{tabular}{|c|c|c|c|c|c|c|c|c|c|c|}
\hline & \multirow{2}{*}{$\begin{array}{l}E_{\text {inc }} \\
(\mathrm{nJ})\end{array}$} & \multirow{2}{*}{$\begin{array}{l}\text { Caffeine } \\
(\mathrm{mM})\end{array}$} & \multirow{2}{*}{$\begin{array}{l}T \\
(\mathrm{~h})\end{array}$} & \multirow{2}{*}{$\begin{array}{l}\text { Number } \\
\text { of } \\
\text { mitoses }\end{array}$} & \multicolumn{6}{|c|}{ Number of metaphase plates classes $A-E$} \\
\hline & & & & & A & B & $\mathrm{C}$ & $\mathrm{D}$ & $\mathbf{E}$ & \\
\hline \multicolumn{11}{|c|}{ Unsynchronized } \\
\hline \multirow[t]{2}{*}{ V79 cells } & 1 & 2.0 & 7 & 82 & 68 & 14 & 0 & 0 & 0 & $(0 \leqslant p \leqslant 0.04)$ \\
\hline & 1 & 2.0 & 13 & 75 & 73 & 2 & 0 & 0 & 0 & $(0 \leqslant p \leqslant 0.05)$ \\
\hline \multicolumn{11}{|c|}{ Synchronized } \\
\hline \multirow[t]{3}{*}{ V79 cells } & 1 & 2.0 & 14 & 70 & 66 & 2 & 0 & 0 & 2 & $(0.003 \leqslant p \leqslant 0.09)$ \\
\hline & 1 & 1.0 & 14 & 96 & 89 & 5 & 0 & 0 & 2 & $(0.002 \leqslant p \leqslant 0.07)$ \\
\hline & 2 & 1.0 & 14 & 61 & 59 & 1 & 0 & 0 & 1 & $(0 \leqslant p \leqslant 0.09)$ \\
\hline
\end{tabular}

$E_{\text {inc }}(\mathrm{nJ})$, incident UV energy applied per microirradiated cell.

$T$ (h), post-incubation period with 1 and $2 \mathrm{mM}$ caffeine, respectively.

For the number of mitoses of class E (classes E1 +E2), the lower and upper limits of the $95 \%$ confidence intervals are given in parentheses. 


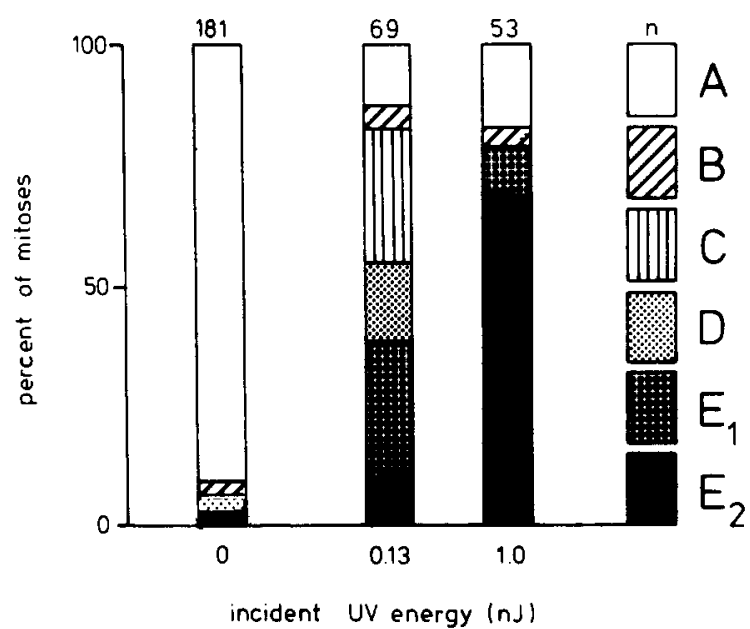

Fig. 6. Chromosome damage produced by UV microirradiation of the cell nucleus of synchronized V79 cells and post-treatment with caffeine $(1 \mathrm{mM})$. Synchronized cell populations were established by shaking off mitotic cells from growing cultures. A small part of the cell nucleus was microirradiated between 3 and $5 \mathrm{~h}$ thereafter, when most of the cells were in G1 and early $S$ phase, respectively. The incident $U V$ energy per nucleus was $0,0.13$ and $1.0 \mathrm{~nJ}$. Chromosome preparations were made $19 \mathrm{~h}$ after mitotic selection. Columns show the distribution of damage classes A-E2 as a function of the incident energy. The number of evaluated mitotic cells is given at the top of each column.

cycle, respectively, indicates that shorter incubation times resulted in a significantly higher percentage of classes C, D and E1. Class El metaphases obtained after $7 \mathrm{~h}$ often contained a "damage center" (Fig. Ib). By contrast, pulverization of the whole-chromosome complement (class E2) was rarely observed after $7 \mathrm{~h}$ but became predominant after $16 \mathrm{~h}$.

As in whole-cell irradiation experiments, labeling of cells with $\left[{ }^{3} \mathrm{H}\right]$ thymidine showed that chromosome shattering only occurred in cells which, after microirradiation, had performed semiconservative DNA synthesis.

In other experiments (Fig. 6), synchronized cells [Gl/early S phase, see Material and Methods] were microirradiated with 2 doses $(0.13$ and $1.0 \mathrm{~nJ})$ and post-incubated with $1 \mathrm{mM}$ caffeine for $14-16 \mathrm{~h}$. At the lower dose $(0.13 \mathrm{~nJ})$, the fraction of classes $\mathrm{E}$ was significantly reduced $(38 \%, 0.28 \leqslant p \leqslant 0.52)$ compared with $1.0 \mathrm{~nJ}(79 \%, 0.65 \leqslant p$ $\leqslant 0.89$ ), and most metaphase plates with GCS showed chromatid fragmentation rather than complete pulverization. At this lower energy, a significantly higher fraction of metaphase plates showed damage attributable to classes $C$ and $D$.

Similar experiments were performed without caffeine post-treatment. Unsynchronized cells were microirradiated with 0.53 or $1 \mathrm{~nJ}$, and sampled after $7 \mathrm{~h}$ ( 56 metaphase spreads obtained) or $13 \mathrm{~h}$ (110 metaphase spreads). Synchronized cells were microirradiated at G1/early S with $1 \mathrm{~nJ}$, and a total of 195 metaphase spreads was obtained after 14,17 and $21 \mathrm{~h}$ post-incubation. The maximal proportion of cells with GCS observed in these series of experiments was $2.4 \%(0 \leqslant p \leqslant 0.08)$. In addition, a slight but not significant increase of class $C$ (up to $3.6 \%, 0 \leqslant p \leqslant 0.06$ ) was found; however, no localized chromosome pulverization was noted. 
(2) Microirradiation of the cytoplasm. To establish a possible effect of cytoplasmic irradiation, the cytoplasm of V79 cells was microirradiated at a distance of 4-5 $\mu \mathrm{m}$ beside the edge of the nucleus, and cells were post-incubated with caffeine ( 1 or $2 \mathrm{mM}$ ). Chromosome preparations were performed 7,13 and $14 \mathrm{~h}$ after microirradiation of 1450 cells in unsynchronized cultures. A total of 1817 synchronized cells was microirradated $3-5 \mathrm{~h}$ after mitotic selection, and chromosome preparations were made $14 \mathrm{~h}$ later. Mitotic indices in experimental fields varied between 8.6 and $15.6 \%$ and were similar to mitotic indices of unirradiated cells in the same petri dishes. Table 1 shows that chromosome shattering is a rare event after microirradiation of the cytoplasm even at an incident dose of $2 \mathrm{~nJ}$ per cell. This dose is twice as high as the maximal dose used in the partial nuclear irradiation experiments and compensates for the reduced absorption of the cytoplasm at 257 $\mathrm{nm}$, which is known to be about $50 \%$ of that of the nucleus (Hatfield et al., 1970). GCS was found in 5 out of 384 mitoses obtained after partial cytoplasmic irradiation. These few cells with shattered chromosomes were possibly due to erroneous microirradiation of the nucleus. It is concluded that the cytoplasm does not contain the targets important for the induction of shattering.

(3) Estimate of the UV fluence remote from the irradiation site in microirradiated nuclei. A trivial explanation of GCS after partial nuclear irradiation could be the effect of stray ultraviolet radiation. If UV fluences in nuclear areas remote from the site of microirradiation, owing to radiation scattering, were higher than the "threshold"
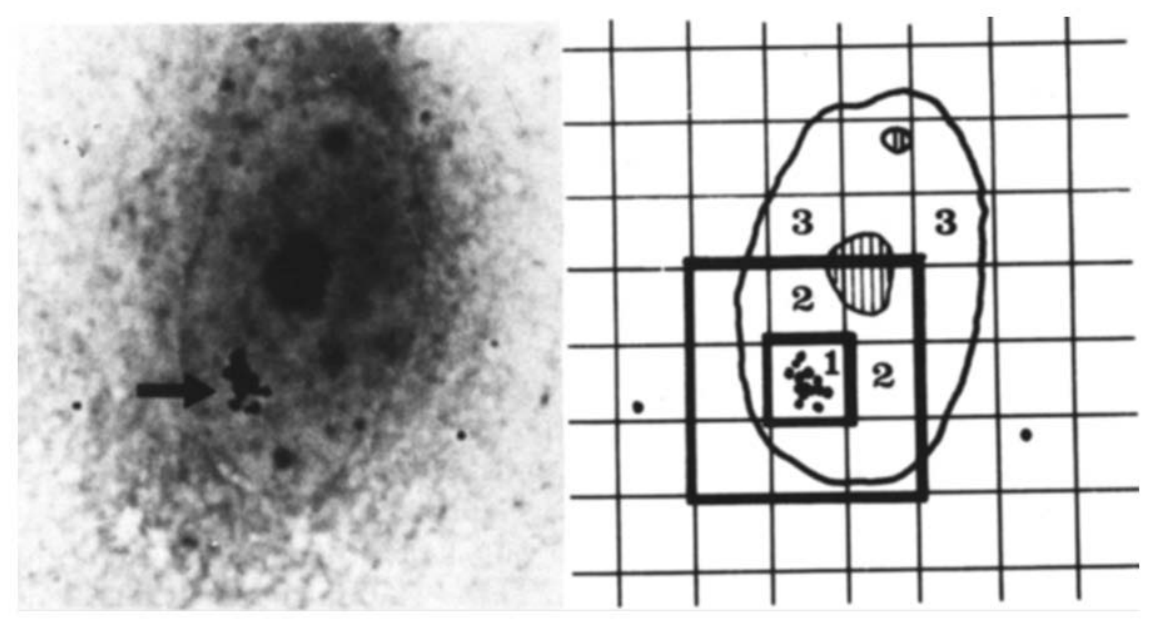

Fig. 7. Principle of quantitative evaluation of UDS possibly induced remote from the irradiation site. Left, autoradiograph of the nucleus of a Chinese hamster cell (CHL) after UV microirradiation in GI and incubation with $\left[{ }^{3} \mathrm{H}\right]$ thymidine for $2 \mathrm{~h}$. Silver grains (arrow) indicate unscheduled DNA synthesis at the site of microirradiation. Right, schematic drawing of the same nucleus. By using an ocular grid having $4-\mu \mathrm{m}$ squares, the nuclear area was divided into three parts: 1 , irradiation site; 2 , squares over nuclear area adjacent to the irradiation site; 3 , squares over nuclear area remote from the irradiation site. 
fluence established for GCS in whole-cell irradiation experiments, GCS in microirradiated nuclei would be easily explained. After laser-UV-microirradiation of CHL cells (Zorn et al., 1979; T. Cremer et al., 1980), UDS was concentrated at the irradiation site and adjacent regions (areas 1 and 2, Fig. 7); in the area remote from the irradiation site (area 3, Fig. 7), no microirradiation-induced increase of UDS compared with that in unirradiated nuclei was observed (Zorn et al., 1979; T. Cremer et al., 1980). This finding, however, did not exclude the possibility that the UDS response of cells after microirradiation was so altered that a high amount of DNA photolesions in one part of the nucleus decreased the cell's ability to perform excision repair in the rest of the nucleus. If so, considerable amounts of DNA photolesions in this part due to scattered UV radiation might have remained undetected. To obtain an upper limit of the UV flux possible in area 3, partial nuclear irradiation of CHL cells in G1 with an incident UV dose of 0 and $1 \mathrm{~nJ}$ was followed by whole-cell irradiation with a UV fluence of 0 and $1.7 \mathrm{~J} / \mathrm{m}^{2}$, i.e., the threshold fluence which had to be exceeded for the induction of GCS in V79 cells post-treated with $1 \mathrm{mM}$ caffeine (compare Figs. 2 and 4).

Autoradiographs were evaluated after pulse labeling with $\left[{ }^{3} \mathrm{H}\right]$ thymidine for $2 \mathrm{~h}$. Table 2 shows the average number of silver grains \pm S.D.M. per square unit $\left(16 \mu \mathrm{m}^{2}\right)$ established (a) over area 3, and (b) over the whole area of nuclei which were not microirradiated. In the absence of whole-cell irradiation, grain densities over the remote area did not significantly differ from grain densities over control nuclei. A significant increase of the number of silver grains per square unit in area 3 , however, was noted after additional whole-cell irradiation (with $1.7 \mathrm{~J} / \mathrm{m}^{2}$ ). This indicates that the UV fluence in this area which possibly resulted from scattered UV radiation was significantly lower than $1.7 \mathrm{~J} / \mathrm{m}^{2}$.

TABLE 2

EFFECT OF MICROIRRADIATION $(\lambda, 257 \mathrm{~nm})$ OF THE NUCLEUS PLUS WHOLE-CELL IRRADIATION $(\lambda, 254 \mathrm{~nm})$ ON UNSCHEDULED DNA SYNTHESIS REMOTE FROM THE SITE OF MICROIRRADIATION

\begin{tabular}{lll}
\hline Microirradiation $(\mathrm{nJ})$ & \multicolumn{2}{l}{ Whole-cell irradiation $\left(\mathrm{J} / \mathrm{m}^{2}\right)$} \\
\cline { 2 - 3 } & $0 \mathrm{~J} / \mathrm{m}^{2}$ & $1.7 \mathrm{~J} / \mathrm{m}^{2}$ \\
\hline 0 & $1.04 \pm 0.06$ & $3.68 \pm 0.16$ \\
& $(n=127)$ & $(n=104)$ \\
1 & $1.13 \pm 0.44$ & $2.23 \pm 0.24$ \\
& $(n=56)$ & $(n=72)$ \\
\hline
\end{tabular}

Partial nuclear irradiation of CHL cells in GI with an incident UV dose of 0 and $1 \mathrm{~nJ}$ was followed by whole-cell irradiation with a UV fluence of 0 and $1.7 \mathrm{~J} / \mathrm{m}^{2}$, and pulse labeling with $\left[{ }^{3} \mathrm{H}\right]$ thymidine. The average number of silver grains \pm SDM per square unit $\left(16 \mu \mathrm{m}^{2}\right)$ is shown, established over the area remote from the irradiation site $(:=$ area 3 , Fig. 7) in case of microirradiated cells $(1 \mathrm{~nJ})$, and over the whole nuclear area in case of cells not microirradiated $(0 \mathrm{~nJ})$.

$n$, number of nuclei evaluated. 
A theoretical estimate of the UV fluence to be expected at a distance of $10 \mu \mathrm{m}$ from the site of microirradiation due to scatter of ultraviolet radiation gives a UV fluence of 0.034 and $0.07 \mathrm{~J} / \mathrm{m}^{2}$ for the incident energies 1 and $2 \mathrm{~nJ}$, respectively ( $\mathrm{T}$. Cremer et al., 1980).

Thus both experimental evidence and theoretical considerations indicate that the UV fluence to be expected in the area remote from the irradiation site was not sufficient to account for GCS per se.

\section{Discussion}

Severe chromosome fragmentation and/or pulverization has been observed in many cell systems and after a variety of treatments (Chu, 1965; Nichols, 1970, 1974; Kihlman, 1977). In the present investigation we compared the effects of whole-cell UV irradiation $(\lambda, 254 \mathrm{~nm})$ and UV microirradiation $(\lambda, 257 \mathrm{~nm})$ plus caffeine post-treatment on the induction of chromosome shattering (CS). We use this term to avoid any prejudice about its mechanism; we suggest that fragmentation and pulverization may represent 2 different manifestations of the same process. When the findings of this investigation are placed in context with the observations of chromosome pulverization/fragmentation reported by other authors, several possibilities may be considered. Chromosome shattering might be due to a breakdown of DNA synthesis (Freed and Schatz, 1969; Kihlman, 1977) or to premature chromosome condensation (for review see Sperling and Rao, 1974) obtained by a number of treatments (Nichols et al., 1964, 1965; Stich et al., 1964; Zur Hausen, 1967; Kato and Sandberg, 1968a,b; Schor et al., 1975). In any discussion of these or other possibilities, several features of generalized (GCS) and partial chromosome shattering (PCS), as observed here, should be noted.

(1) Under the conditions investigated, the frequency of GCS and PCS was very low after UV irradiation alone and caffeine treatment alone but high after the combined treatment (see text and Figs. 2, 4, 6).

(2) Microirradiation of the cytoplasm plus caffeine post-treatment did not significantly increase the percentage of cells with chromosome shattering (Table 1).

(3) GCS and PCS occurred at the first post-irradiation mitosis in cells with a single microirradiated nucleus, as shown by follow-up studies of single microirradiated cells in phase contrast (T. Cremer et al., 1981, and our unpublished data). No association of a complement of normally condensed metaphase chromosomes with the shattered one was observed. This indicates that cell fusion or asynchrony between nuclei in multinucleated cells is not involved in CS obtained by UV irradiation and caffeine post-treatment.

(4) GCS and PCS, following partial nuclear irradiation and post-treatment with caffeine, were observed in 2 Chinese hamster cell lines of different origin, V79 cells (T. Cremer et al., 1980) and M3-1 cells (our unpublished results), and in early passages of euploid Chinese hamster cells (CHL) derived from lung tissue (Zorn et al., 1976).

(5) If chromosome shattering is associated with a breakdown of DNA synthesis 
or with some kind of premature chromosome condensation, one should expect that shattered chromosomes represent chromatin in the state of replication and thus contain a DNA value between $2 \mathrm{C}$ and $4 \mathrm{C}$ levels.

Feulgen measurements of the DNA content of V79 cells with GCS obtained by PUVA-irradiation and post-incubation with caffeine revealed (T. Cremer et al., 1981) that, within experimental error (ca. 8\%), the cells had a normal $G_{2}$ M-DNA content. The same results were obtained by flow cytometry (Horan and Wheeless, 1977) for M3-1 cells after UV irradiation at $254 \mathrm{~nm}$ and caffeine post-treatment (Cremer and Gray, submitted).

When $\left[{ }^{3} \mathrm{H}\right]$ thymidine was added to V79 cultures $1 \mathrm{~h}$ before chromosome preparation was performed without colchicine pretreatment, about $90 \%$ of cells with GCS were unlabeled (Zorn, 1978). These results indicate that CS is produced by a process which does not grossly interfere with DNA replication. Instead, a more subtle process of misreplication might be considered which results in a failure of normal chromosome condensation.

We have previously established the hypothesis (T. Cremer et al., 1980, 1981) that photochemically induced DNA lesions produced in microirradiated chromosome territories of the interphase nucleus (Zorn et al., 1979; C. Cremer et al., 1980a) may induce shattering of unirradiated chromosomes situated in territories remote from the irradiation site. We considered several possibilities to explain the synergistic effect of UV irradiation and caffeine within the framework of this hypothesis and proposed a factor depletion model for the induction of GCS (T. Cremer et al., 1980, 1981). The hypothesis is based on the assumption that the cell nucleus contains factors needed for daughter-strand repair and normal semiconservative DNA replication as well. Misreplication is induced when the pool of these critical factors becomes exhausted during the $\mathbf{S}$ phase. The model allows several predictions which are consistent with the present experimental results. (a) The cell has to traverse some part of $S$ in order to accumulate a critical number of daughter-strand repair sites in the presence of caffeine. With increasing UV dose, the amount of irradiated DNA that has to be replicated after irradiation to reach this critical limit would become smaller; exhaustion of the pool would take place at a correspondingly earlier stage. Thus, a higher dose should not only increase the yield of GCS, but also increase the fraction of cells that show chromosome pulverization (class E2) instead of chromosome fragmentation (class E1). The same line of reasoning is valid for the effect of irradiation at different stages of the cell cycle. The percentage of cells with GCS as well as the ratio of class E2/E1 is expected to be higher when irradiation is performed in $\mathrm{Gl}$ /early $\mathrm{S}$ as compared with later stages of $\mathrm{S}$. The dose-effect relationship obtained for the induction of GCS (Figs. 2,4) may simply reflect the variation of the pool size in the irradiated cell populations. Notably, the percentage of PCS increased when microirradiation was either performed at later stages of $S$ (Fig. 5) or at a lower incident dose in G1/early S (Fig. 6). To account for PCS in the light of the factor-depletion model, we assume that microirradiated chromosome domains are more sensitive to depletion of $F$ than are unirradiated ones. If so, this difference in sensitivity may become more obvious in cases where factor depletion does occur only for a short period of the $\mathrm{S}$ phase. In these cases, chromosome 
shattering may be predominantly or even completely restricted to the microirradiated chromatin (Zorn et al., 1976). This idea is supported by 2 observations. Firstly, the damaged chromosomes are not randomly distributed in the metaphase plate, but clearly centered around a damage center (Fig. 1a). Secondly, evaluation of PCS in microirradiated CHL cells has shown that any chromosome of the complement can take part in PCS with a frequency roughly corresponding with its DNA content (T. Cremer et al., in preparation).

In conclusion, the data obtained by UV microirradiation of the nucleus and caffeine post-treatment suggest 2 levels of chromosomal alterations induced: level 1 as indicated by PCS appears to be largely restricted to irradiated chromatin, while level 2 involves both irradiated and unirradiated chromatin and results in GCS.

\section{Acknowledgement}

This work was supported by grants from the Deutsche Forschungsgemeinschaft (WO 148/16 and SFB 46). We are greatly indebted to Drs. C.F. Arlett, A.V. Carrano, A.R. Lehmann and G. Obe for stimulating discussions and valuable comments on the manuscript, and to Drs. F. Vogel and U. Wolf for continuous support and encouragement.

\section{References}

Bender, M.A, H.G. Griggs and P.L. Walker (1973) Mechanisms of chromosomal aberration production, I. Aberration induction by UV light, Mutation Res., 20, 387-402.

Chu, E.H.Y. (1965) Effects of ultraviolet radiation on mammalian cells, I. Induction of chromosome aberrations, Mutation Res., 2, 75-94.

Cremer, C., and J.W. Gray, Induction of generalized chromosome shattering by ultraviolet light and caffeine: DNA content of whole cells as determined by flow cytometry, submitted.

Cremer, C., C. Zorn and T. Cremer (1974) An ultraviolet laser microbeam for $257 \mathrm{~nm}$, Microsc. Acta, 75 , 331-337.

Cremer, C., T. Cremer, C. Zorn and L. Schoeller (1976) Effects of laser-UV-microirradiation $(\lambda=2573 \AA$ ) on proliferation of Chinese hamster cells, Radiat. Res., 66, 106-121.

Cremer, C., C. Zorn, T. Cremer and V. Cioreanu (1978) UV-Induced unscheduled DNA synthesis in Chinese hamster cells: The influence of the ${ }^{3} \mathrm{H}$-thymidine concentration, Arch. Genet., 5I, 2-3.

Cremer, C., T. Cremer, M. Fukuda and K. Nakanishi (1980a) Detection of laser-UV-microirradiation induced DNA photolesions by immunofluorescent staining, Hum. Genet., 54, 107-110.

Cremer, C., T. Cremer and M. Simickova (1980b) Induction of chromosome shattering and miocronuclei by ultraviolet light and caffeine, 1. Temporal relationship and antagonistic effects of the four deoxyribonucleosides, Environ. Mutagen., 2, 339-351.

Cremer, T., C. Cremer, J. Zimmer and C. Zorn (1980) UV-Microirradiation of Chinese hamster cells and posttreatment with caffeine: Indication for clastogenic effects remote fom the irradiation site, in: $H$. Altmann, E. Riklis and H. Slor (Eds.), DNA Repair and Late Effects, Nuclear Research Center, Negev, Israel, pp. 53-62.

Cremer, T, S. Peterson, C. Cremer and M.W. Berns (1981) Laser microirradiation of Chinese hamster cells at wavelength $365 \mathrm{~nm}$ : Effects of psoralen and caffeine, Radiat. Res., 85, 529-543.

Evans, H.J. (1977) Molecular mechanisms in the induction of chromosome aberrations, in: D. Scott, B.A. Bridges and F.H. Sobels (Eds.), Progress in Genetic Toxicology, Elsevier/North-Holland, Amsterdam, pp. 57-74. 
Freed, J.J., and S.S. Schatz (1969) Chromosome aberrations in cultured cells deprived of single essential amino acids, Exp. Cell Res., 55, 393-409.

Hatfield, J.M.R., L. Schulze and D. Ernst (1970) Measurement of the ultraviolet absorption in specific parts of both living and fixed mammalian cells, using a specially designed microspectrophotometer, Exp. Cell Res., 59, 484-486.

Horan, P.K, and L.L. Wheeless Jr. (1977) Quantitative single cell analysis and sorting, Science, 198, $149-157$.

Kato, H., (1973) Induction of sister chromatid exchanges by UV light and its inhibition by caffeine, Exp. Cell Res., 82, 383-390.

Kato, H., and A.A. Sandberg (1968a) Chromosome pulverization in human cells with micronuclei, J. Nat. Cancer Inst., 40, 165-179.

Kato, H, and A.A. Sandberg (1968b) Chromosome pulverization in Chinese hamster cells induced by Sendai virus, J. Nat. Cancer Inst., 41, 1117-1123.

Kihlman, B.A. (1977) Caffeine and Chromosomes, Elsevier, Amsterdam.

Kihlman, B.A., S. Sturelid, B. Hartley-Asp and K. Nilsson (1974) The enhancement by caffeine of the frequencies of chromosomal aberrations induced in plant and animal cells by chemical and physical agents, Mutation Res., 26, 105-122.

Kihlman, B.A., A.T. Natarajan and H.C. Andersson (1978) Use of the 5-bromodeoxyuridine-labelling technique for exploring mechanisms involved in the formation of chromosomal aberrations, I. G2 experiments with root-tips of Vicia faba, Mutation Res., 52, $181-198$.

Leenhouts, H.P, and K.H. Chadwick (1978) The crucial role of DNA double-strand breaks in cellular radiobiological effects, Adv. Radiat. Biol., 7, 55-101.

Lehmann, A.R. (1976) Postreplication repair of DNA in mammalian cells: A discussion of the mechanism and biological importance, in: J. Kiefer (Ed.), Proc. in Life Sciences: Radiation and Cellular Control Processes, Springer, Berlin, pp. 147-158.

Nichols, W.W. (1970) Virus-induced chromosome abnormalities, Annu. Rev. Microbiol., 24, 479-500.

Nichols, W.W. (1974) Viruses and chromosomes, in: H. Busch (Ed.), The Cell Nucleus, Vol. II, Academic Press, New York, pp. 437-458.

Nichols, W.W., A. Levan, P. Aula and E. Norby (1964) Extreme chromosome breakage induced by measles virus in different in vitro systems, Hereditas, 51, 380-382.

Nichols, W.W., A. Levan, P. Aula and E. Norby (1965) Chromosome damage associated with the measles virus in vitro, Hereditas, $54,101-118$.

Nilsson, K., and A.R. Lehmann (1975) The effect of methylated oxypurines on the size of newly-synthesized DNA and on the production of chromosome aberrations after UV-irradiation in Chinese hamster cells, Mutation Res., 30, 255-266.

Roberts, J.J. (1978) The repair of DNA modified by cytotoxic, mutagenic, and carcinogenic chemicals, Adv. Radiat. Biol., 7, 211-436.

'Roberts, J.J., J.E. Sturrock and K.N. Ward (1974) The enhancement by caffeine of alkylation-induced cell death, mutations and chromosomal aberrations in Chinese hamster cells, as a result of inhibition of post-replication DNA repair, Mutation Res., 26, 129-143.

Schor, S.L., R.T. Johnson and C.A. Waldren (1975) Changes in the organization of chromosomes during the cell cycle, Response to ultraviolet light, J. Cell Sci., 17, 539-565.

Sperling, K., and P.N. Rao (1974) The phenomenon of premature chromosome condensation: Its relevance to basic and applied research, Humangenetik, 23, 235-258.

Stich, H.F., G.L. van Hoosier and J.J. Trentin (1964) Viruses and mammalian chromosomes, Chromosome aberrations by human adenovirus type 12, Exp. Cell Res., 34, 400-403.

Wolff, S. (1972) Chromosome aberrations induced by ultraviolet radiation, Photophysiol., 7, 189-205.

Zorn, C. (1978) Mikrobestrahlungsexperimente zur synergistischen Chromosomenschädigung durch ultraviolettes Licht und Coffein in Zellen des Chinesischen Hamsters: Untersuchungen zum Mechanismus und mögliche Anwendungen, Thesis, University of Freiburg i. Br.

Zorn, C., T. Cremer, C. Cremer and J. Zimmer (1976) Laser-UV-microirradiation of interphase nuclei and post-treatment with caffeine, $A$ new approach to establish the arrangement of interphase chromosomes, Hum. Genet., 35, 83-89. 
Zorn, C., C. Cremer, T. Cremer and J. Zimmer (1979) Unscheduled DNA synthesis after partial UV-irradiation of the cell nucleus, Distribution in interphase and metaphase, Exp. Cell Res., 124, 111-119.

Zur Hausen, H. (1967) Chromosomal changes of similar nature in seven established cell lines derived from the peripheral blood of patients with leukemia, J. Nat. Cancer Inst., 38, 683-696. 